\title{
Acute inflammatory demyelinating polyneuritis in association with an asymptomatic infection by SARS-CoV-2
}

\author{
Martina Bracaglia ${ }^{1}$ [ $\cdot$ Ilaria Naldi ${ }^{1} \cdot$ Alessandra Govoni $^{2} \cdot$ Donatella Brillanti Ventura $^{3} \cdot$ Patrizia De Massis $^{1}$
}

Received: 24 May 2020 / Revised: 14 June 2020 / Accepted: 18 June 2020 / Published online: 25 June 2020

c) Springer-Verlag GmbH Germany, part of Springer Nature 2020

\section{Dear Sirs,}

After the recognition of COVID-19 disease, caused by the SARS-CoV-2, several reports refer to neurological symptoms in such patients [1, 2], including Guillain-Barré Syndrome (GBS) [3-9]

We describe a case of acute demyelinating polyneuritis in association with asymptomatic SARS-CoV-2 infection.

A 66-years old Maroccan woman, the resident in the Bologna area, was admitted to Imola Hospital on March 15th, 2020, for hyposthenia in all limbs, severe in lower, with a Medical Research Council (MRC) scale of $1 / 5$ in distal and 2/5 in proximal of the lower extremities and 3/5 in distal and 4/5 in proximal of the upper extremities, with a distal tingling sensation and pronounced lumbar pain for about eight days. She was unable to walk, reported difficulty in swallowing and speeching, tendon reflexes were abolished. Vital signs were normal, medical history was negative and no infection was reported in the previous month.

We hypothesized GBS and performed nerve conduction studies consistent with demyelinating polyneuropathy (Tables 1,2) and cerebrospinal fluid (CSF) analysis, consistent with our hypothesis (protein content $245 \mathrm{mg} / \mathrm{dL}$, cells $13 / \mathrm{mmc}$, polymorphonucleate $61.5 \%$ ).

Microbiologic testing on CSF and serum was negative (HSV1-2, EBV, VZV, CMV, HIV, Mycoplasma Pneumoniae, Borrelia). Anti-ganglioside antibodies were negative. We

Martina Bracaglia, Ilaria Naldi and Patrizia De Massis contributed equally.

Martina Bracaglia

m.bracaglia@ausl.imola.bo.it

1 Neurology Unit, Medical Oncological Department, S. Maria Della Scaletta Hospital, 40026 Imola, BO, Italy

2 Internal Medicine, Medical Oncological Department, S. Maria Della Scaletta Hospital, 40026 Imola, BO, Italy

3 Montecatone Rehabilitation Institute, 40026 Imola, BO, Italy excluded electrolytic abnormalities, heavy metal or drugs toxicity, endocrinological disorders, folate and vitamin B12 deficiency.

Blood analysis showed elevated CPK (461 U/L, nor$\mathrm{mal}<145)$, CRP $(5.65 \mathrm{mg} / \mathrm{dL}$, normal $<0.5)$, lymphocytopenia $\left(0.68 \times 10^{9} / \mathrm{L}\right.$, normal $\left.1 \cdot 10-4\right)$, mild increase of LDH (284 U/L, normal <248), GOT and GPT (549 and 547 U/L, normal $<35$ ), similarly to COVID-19 patients laboratory profile [10].

Thus, considering the rapid spread of this infection in our region and its pandemic extent, we decided to perform a RT-PCR for SARS-CoV-2 on nasopharyngeal swab, which resulted positive.

We found elevation of Interleukin $6(11 \mathrm{pg} / \mathrm{mL}$, normal <5.9), also associated with Covid-19 disease [10]. She was transferred to Covid-19 department and received a five days course of intravenous immune globulin (IvIg), ritonavir $100 \mathrm{mg}$ and darunavir $800 \mathrm{mg}$ per day with hydroxychloroquine $200 \mathrm{mg}$ twice daily, according to our hospital protocol for COVID-19 treatment. She never developed respiratory symptoms or fever; thoracic CT scan was normal.

Immediately after IvIg, she significantly improved with a MRC scale of 4/5 in distal of upper limbs and 3/5 both proximal and distal in lower limbs, while facial diplegia has developed.

About 3 weeks after the onset of neurological symptoms two nasopharyngeal swabs, 24 hours apart, resulted negative and she was transferred to rehabilitation care.

To our knowledge, this is the first case of GBS in patient with asymptomatic COVID-19 and laboratory tests consistent with SARS-COV-2 infection. We think the infection wasn't nosocomial, although we cannot absolutely exclude it, because the swab was performed within twelve hours from hospitalization and isolation protocols of suspected patients had been applied. Patient's relatives did not develop symptoms but were observed in isolation for 2 weeks.

The association between COVID-19 and GBS has recently been described both as parainfectious $[3,7,8]$ and 
Table 1 Antidromic sensory nerve conduction studies

\begin{tabular}{lll}
\hline & Amplitude, $\mu \mathrm{V}$ & Conduction velocity, $\mathrm{m} / \mathrm{s}$ \\
\hline Left Median (digit 3-wrist) & $0 \cdot 4$ (n.v. $\geq 17)$ & $32 \cdot 5$ (n.v. $\geq 50)$ \\
Left Ulnar (digit 5-wrist) & Absent & - \\
Right Sup. Peroneal (lateral calf-lateral ankle) & $1 \cdot 2($ n.v. $\geq 6)$ & $50 \cdot 0($ n.v. $\geq 40)$ \\
Righ Sural (calf-posterior ankle) & $1 \cdot 6($ n.v. $\geq 6)$ & $58 \cdot 3($ n.v. $\geq 40)$ \\
Left Sural (calf-posterior ankle) & $1 \cdot 8($ n.v. $\geq 6)$ & $48 \cdot 1$ (n.v. $\geq 40)$ \\
\hline
\end{tabular}

Table 2 Motor nerve conduction studies

\begin{tabular}{|c|c|c|c|c|c|}
\hline & Distal Latency, ms & Amplitude, mV & Conduction velocity, $\mathrm{m} / \mathrm{s}$ & F latency, ms & $\begin{array}{l}\text { cMAP } \\
\text { Duration, ms }\end{array}$ \\
\hline \multicolumn{6}{|l|}{ Left Median } \\
\hline Wrist-APB & $9 \cdot 9(\mathrm{n} . \mathrm{v} \leq 4 \cdot 4)$ & $2 \cdot 6($ n.v. $\geq 4 \cdot 4)$ & & $45 \cdot 5($ n.v. $\leq 31)$ & 21.4 \\
\hline Antecub. fossa-wrist & $13 \cdot 3$ & $2 \cdot 6$ & $57 \cdot 4$ (n.v. $\geq 50)$ & & \\
\hline \multicolumn{6}{|l|}{ Left Ulnar } \\
\hline Wrist-ADM & $6 \cdot 2($ n.v. $\leq 3 \cdot 3)$ & $2 \cdot 5($ n.v. $\geq 6 \cdot 0)$ & & $41 \cdot 5$ (n.v. $\leq 32)$ & 33.1 \\
\hline Below elbow-wrist & 11 & $1 \cdot 7$ & $39 \cdot 6$ (n.v. $\geq 50)$ & & \\
\hline Ab.elbow-bel.elbow & $15 \cdot 4$ & $1 \cdot 4$ & $36 \cdot 4$ & & \\
\hline \multicolumn{6}{|l|}{ Left Tibial } \\
\hline Ankle-AHB & $12 \cdot 8($ n.v. $\leq 5 \cdot 8)$ & $1 \cdot 8($ n.v. $\geq 4 \cdot 0)$ & & Absent (n.v. $\leq 56)$ & 38.2 \\
\hline Popliteal fossa-ankle & $23 \cdot 8$ & $1 \cdot 3$ & $34 \cdot 1$ (n.v. $\geq 41)$ & & \\
\hline \multicolumn{6}{|l|}{ Right Tibial } \\
\hline Ankle-AHB & $11 \cdot 3($ n.v. $\leq 5 \cdot 8)$ & $1 \cdot 1($ n.v. $\geq 4.0)$ & & Absent (n.v. $\leq 56)$ & 42.7 \\
\hline Popliteal fossa-ankle & 18.9 & $1 \cdot 0$ & $48 \cdot 7$ (n.v. $\geq 41)$ & & \\
\hline \multicolumn{6}{|l|}{ Left Peroneal } \\
\hline Ankle-EBD & $14 \cdot 3(\mathrm{n} . \mathrm{v} \leq 0 \cdot 1)$ & $0 \cdot 1(\mathrm{n} . \mathrm{v} \geq 2 \cdot 0)$ & & Absent (n.v. $\leq 56)$ & 30.8 \\
\hline Bel.fibula-ankle & $22 \cdot 8$ & $0 \cdot 4$ & $30 \cdot 6$ (n.v. $\geq 41)$ & & \\
\hline Ab.fibula-bel.fibula & $26 \cdot 1$ & $0 \cdot 5$ & $30 \cdot 3$ & & \\
\hline \multicolumn{6}{|l|}{ Right Peroneal } \\
\hline Ankle-EBD & $7 \cdot 4(\mathrm{n} . \mathrm{v} \leq 0 \cdot 1)$ & $3 \cdot 0($ n.v. $\geq 2 \cdot 0)$ & & Absent (n.v. $\leq 56)$ & 19.8 \\
\hline Bel.fibula-ankle & 16 & $1 \cdot 8$ & $30 \cdot 2$ (n.v. $\geq 41)$ & & \\
\hline Ab.fibula-bel.fibula & 19. & $1 \cdot 8$ & $28 \cdot 9$ & & \\
\hline
\end{tabular}

Distal compound muscle action potentials (cMAP) showed reduced amplitude because of temporal dispersion due to demyelination

$A P B$ abductor pollicis brevis, $A D M$ abductor digiti minimi, $A H B$ abductor hallucis brevis, $E B D$ extensor digitorum brevis, $n . v$. normal value

as post-infective event $[4,5,9]$, similar to other infections and coronavirus $[11,12]$, suggesting a mechanism of molecular mimicry or part of systemic inflammatory cascade triggered by the virus. Facial diplegia seems recurrent in GBS related to COVID-19 [7, 8].

Interesting in our case a patient asymptomatic for COVID-19 develops neurological impairment as a unique clinical event, probably as part of dysimmune process.

Unfortunately, we could not perform a serological test or CSF PCR for COVID-19.

We believe this association may not be a coincidence, more cases could be evaluated, possibly supported by serological and CSF tests, and underlines the importance of looking for neurological impairment in COVID-19 disease and address the correct treatment, such as IvIg, also for respiratory function worsening independently from pneumonitis.

Author contributions BM treated the patient and collected the clinical information. BM, NI and PDM drafted the manuscript. BM and PDMperformed the NCS analysis. PDM provided guidance for the diagnosis and clinical management of the patient. All authors contributed to the editing of the manuscript and approved the final version.

Funding No targeted funding reported.

Availability of data and material De-identified data and material inherent to the case report and not included in the manuscript are available on request to the corresponding author by any qualified investigator. 


\section{Compliance with ethical standards}

Conflicts of interest The authors declare no conflicts of interest relevant to the manuscript.

Ethical approval This article does not contain any studies involving human participant performed by any of the Authors

Informed consent Written informed consent was collected from the patient for the inclusion of de-identified clinical data in a scientific publication, in accordance with the Declaration of Helsinki.

\section{References}

1. Wang HY, Li XL, Yan ZR, Sun XP, Han J, Zhang BW (2020) Potential neurological symptoms of COVID-19. Ther Adv Neurol Disord. https://doi.org/10.1177/1756286420917830

2. Huang C, Wang Y, Li X et al (2020) Clinical features of patients infected with 2019 novel coronavirus in Wuhan, China. Lancet 395(10223):497-506. https://doi.org/10.1016/S0140 -6736(20)30183-5(Epub 2020 Jan 24. Erratum in Lancet 2020 Jan 30)

3. Zhao H, Shen D, Zhou H, Liu J, Chen S (2020) Guillain-Barré syndrome associated with SARS-CoV-2 infection: causality or coincidence? Lancet Neurol 19(5):383-384. https://doi. org/10.1016/S1474-4422(20)30109-5(Epub 2020 Apr 1)

4. Toscano G, Palmerini F, Ravaglia S et al (2020) Guillain-Barrè syndrome associated with Sars-CoV-2. N Engl J Med. https://doi. org/10.1056/NEJMc2009191
5. Padroni M, Mastrangelo V, Asioli GM et al (2020) Guillain-Barré syndrome following COVID-19: new infection, old complication? J Neurol 24:1-3. https://doi.org/10.1007/s00415-020-09849-6

6. Virani A, Rabold E, Hanson T et al (2020) Guillain-Barré syndrome associated with SARS-CoV-2 infection. IDCases 18(20):e00771. https://doi.org/10.1016/j.idcr.2020.e00771

7. Ottaviani D, Boso F, Tranquillini E et al (2020) Early GuillainBarré syndrome in Coronavirus Disease 2019 (COVID-19): a case report from an Italian COVID-hospital. Neurol Sci 41(6):13511354. https://doi.org/10.1007/s10072-020-04449-8(Epub 2020 May 12)

8. Juliao Caamaño DS, Alonso BR (2020) Facial diplegia, a possible atypical variant of Guillain-Barré Syndrome as a rare neurological complication of SARS-CoV-2. J Clin Neurosci. https://doi. org/10.1016/j.jocn.2020.05.016

9. Sedaghat Z, Karimi N (2020) Guillan-Barré syndrome associated with COVID-19 infection: A case report. J Clin Neurosci 76:233-235. https://doi.org/10.1016/j.jocn.2020.04.062

10. Guan WJ, Ni ZY, Hu Y et al (2020) China medical treatment expert group for Covid-19. Clinical characteristics of coronavirus disease 2019 in China. N Engl J Med. 382(18):1708-1720. https ://doi.org/10.1056/NEJMoa2002032(Epub 2020 Feb 28)

11. Uncini A, Shahrizaila N, Kuwabara S (2017) Zika virus infection and GuillainBarré syndrome: a review focused on clinical and electrophysiological subtype. J Neurol Neurosurg Psychiatry $88: 266-271$

12. Kim JE, Heo JH, Kim HO et al (2017) Neurological complications during treatment of middle east respiratory syndrome. J Clin Neurol 13:227-233 